\title{
M-LEARNING FOR THE RECRUITMENT AND SELECTION OF HUMAN TALENT. CASE: INTERVIEW
}

\author{
Paula Asto Machaca and Luis Alfaro Casas \\ Universidad Nacional de San Agustín de Arequipa, Arequipa, Perú
}

\begin{abstract}
The job interview within the recruitment and selection process is a very important activity for both the candidate and the company that requires staff. In order to improve the preparation of the job applicant, many artificial intelligence techniques together with emerging technologies could be used. This paper presents a mobile learning application with two modules for learning and practice using textual case-based reasoning to improve system performance. The document describes the architecture of the design of the system, implementation, and evaluation of mobile learning system. The results of the evaluation show that the mobile learning system is technically feasible, didactic effective and user-friendly.
\end{abstract}

\section{KEYWORDS}

Mobile Learning, Case-Based Reasoning, Textual Case-Based Reasoning, Competency-Based Interview

\section{INTRODUCTION}

The labor demand of the software industry has grown exponentially. It is being reflected in the increase in jobs in online platforms. Analyzing seventeen online job portals according to the five common jobs a systems engineer could do (Analyst, Project Manager, Administrator, Architect, Developer), we select 3 positions with more job offers for study purposes, Developer, Analyst, and Administrator. In Peru, systems engineering and computer science careers are considered one of the highest-paid and many young graduates belong to this family. This reality encourages the employability of more people in the IT field and the great importance of the job interview is reflected, which is the technique most used in the recruitment and selection of human talent in companies (Blasco 2004). The job interview is usually the most relevant filter in the incorporation of adequate personnel for the positions that are required in a given organization. On the other hand, mobile learning associated with artificial intelligence techniques is among the most popular technologies, whose importance has been driven by the growth of mobile device use, emerging as a useful tool for education in general. However, far too little attention has been paid to the use of these emerging technologies in the recruitment and selection process of human talent.

The aim of this paper is to discuss an m-learning system to prepares the applicant with fundamental notions of the interview and provides a selection of cases using artificial intelligence techniques and emerging technology tools to facilitate this task. The remaining part of the paper is organized as follows. A brief review of the state-of-the-art in this paper is explained in Section 2. Details of the methodology are described in Section 3. Results with the experiment settings are introduced in Section 4. Conclusions and some future works are presented in Section 5.

\section{STATE-OF-THE-ART}

Employers seek certain skills and aptitudes in their workers to play the desired role in a company, but in many cases, desired expectation is not found (Najwa Azmi et al. 2018), this problem contributes to the unemployment problem of recent engineering graduates, people who do not have enough experience required by the industry or in many cases do not have the confidence to be able to face a job interview due to lack of knowledge or nervousness, among others factors. The use of interviews in the recruitment and selection of 
personnel (RSP) (Blackman 2009) is very common because they help in the classification of suitable persons. This practice is not only based on knowledge but on attitudes and/or psychological states. The job interview is an extensive and complex field, for that reason, this study works based on competency-based interviews (McClelland 1973).

The preparation of the candidate towards an interview can be carried out through many technological tools, one of them that shows the greatest potential is mobile learning. This is because mobile phone screens are more versatile than laptops, desktop computers, and televisions. As they are almost always at hand, it means that they are seen in more times and places than other screens (Bridger 2017), have characteristics at any time, any place and can be applied in any profession or activity (Ally 2007) (Traxler 2007) (Alrasheedi and Capretz 2015) (Yorganci 2017) (Hamdani 2013).

There here are several mobile educational platforms, both in the initiative and in developed applications for M-learning (Gnana et al. 2017), but few investigations have been found that focus on supporting this part of the research. Smart teaching can make use of case-based reasoning (CBR) because the best way to learn is through identity learning, where the student identifies with the case presented (Facer et al. 2004), and thanks to the CBR the system can select similar cases from a new entry. CBR is based on the use of historical data as cases or experiences to predict a solution to the current problem, and consists of four phases: RECOVER the most similar cases, REUSE the information and knowledge in these cases to solve the problem, REVIEW the solution proposal and CONSERVE the solution to solve similar cases in the future (Abutair and Belghith 2017) (Aamodt and Plaza 1994). In the case of text handling, a CBR variant called case-based textual reasoning is used. In most of the works consulted on this topic (Elhalwany et al. 2014) (Gerhana et al. 2017) (Ahmed et al. 2008) (Weber et al. 2005) (Delany and Bridge 2006) describes a process for text preprocessing steps that includes filtering, tokenization, and derivation, with certain variants to increase effectiveness, this subprocess is included in the life cycle of the CBR life.

\section{METHODOLOGY}

\subsection{System Features}

Education teaching processes generally consist of theory and practice, but when both notions are connected, there are disputes, however, educational coherence depends on this relationship. Addressing the field of theoretical-practical relations from the didactic is complicated because the subject is ambiguous and elusive, the problem is to recognize the contribution that each one makes to the teaching action (Álvarez 2012). Didactics is a theoretical-practical science because it is essentially about what, how and when to teach, the didactic necessarily implies the practical, and the intervention of the practice demands the technological and artistic theory (technique). For this reason, the M-learning system consists of two modules that will help to better structure the topic and provide the information presented in a simple way.

Theory module Composed by the set of basic concepts of a job interview, distributed and organized to motivate the user's self-learning.

Practical module Includes a selection of cases formulated for a job interview by competencies, applying textual case-based reasoning for the evaluation of the answers entered by the user.

\subsection{Architecture}

The system is built with the Google UI toolkit called flutter that allows creating mobile applications compiled natively to Android and IOS from a single code base, using services offered by firebase such as database, authentication, and storage. The implementation of the system was done using the bloc pattern as a design architecture, which helps in the management of the state and in the access to the data from a central place of the project. The bloc pattern consists of blocs, a bloc is created for each function that is added, and since the flutter is based on the creation of widgets, it is possible to add or delete a widget with a block behind it, without having to worry about affect the code and system in general, it helps the project to be scalable and readable, separating the user interface from the logical part. 
The architecture consists of two important parts. The first part is the mobile client which is mainly composed of the interface, models, repository, util, and blocs that connect the client to the server. The second part is the server which is based on firebase and google libraries that make the backend or system services possible to develop (see Figure 1).

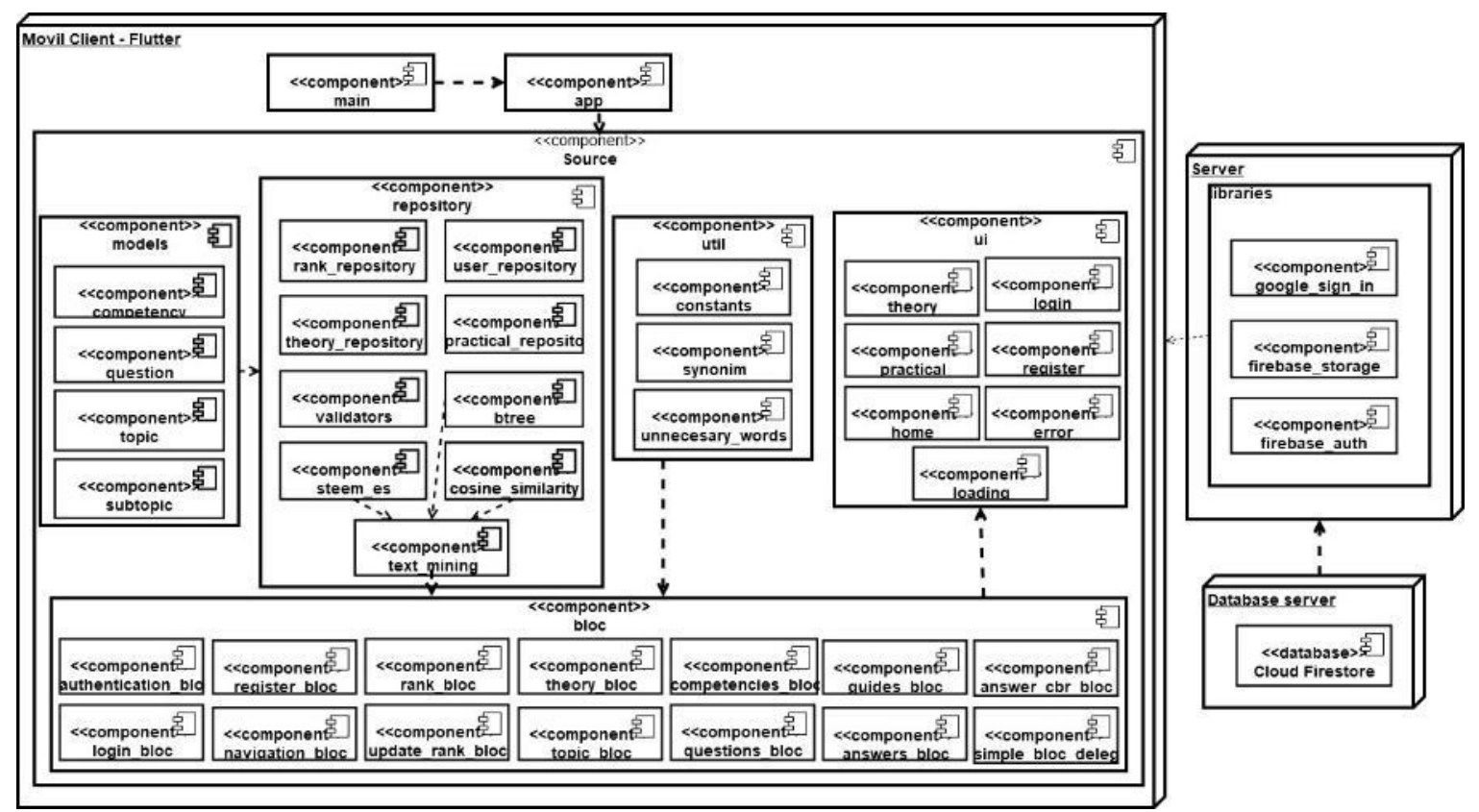

Figure 1. Component diagram representing the architecture of the M-learning system

\subsection{Theory Module}

In the theory module, the concepts of the interview are distributed by grouping them according to the bibliography consulted (see Table 1). The objective of this module is to motivate the user's self-learning. According to the research conducted by Bourgeois, the use of levels to obtain different ranges as the user learns more about a particular subject is a learning strategy used to motivate through rewards called rewards-based learning (Bourgeois et al. 2016).

Table 2. General interview concepts for the theory module grouped according to the bibliography consulted

\begin{tabular}{ll}
\hline Group & Group \\
\hline Interview & Interview phases \\
Interview format & Types of interview \\
Competency-based Interview & Practical suggestions \\
Case study &
\end{tabular}

In the M-learning system, the user can see their progress on the application's home screen. The topics they have consulted will be easily viewed as complete once they have finished. The system is programmed in order to the user can pass levels and reach the rank of "Grand Master of Knowledge in Interviews", which would indicate that they reviewed, completed and/or learned all the topics proposed in the theory module. The ranges that are being considered are described in Table 2.

Table 2. Distribution of ranges by levels proposed for the theory module of the M-learning system

\begin{tabular}{|c|c|c|c|c|c|c|c|}
\hline Rank & Level & Rank & Level & Rank & Level & Rank & Level \\
\hline $\mathrm{Be}$ & 11 & Silver & 13 & $\mathrm{Pl}$ & el 5 & Heroic & 17 \\
\hline Bronze & Level 2 & Gold & Level 4 & Diamond & Level 6 & Grand Master & Level 8 \\
\hline
\end{tabular}




\subsection{Practical Module}

A survey of software companies in the region of Arequipa in Peru was carried out, in order to measure the level of importance they consider for the set of competencies defined after an analysis of several documents that relate the skills that an engineer must have, in the three selected positions (Analyst, Administrator, and Developer). The levels of importance are measured according to the Likert scale from 1 to 5 , where the lowest value represents nothing important and the highest value in very important, the five competencies best classified by position are selected by comparing the sums of the values obtained in the survey, which gives a total of eleven competitions (see Table 3).

Table 3. Selection of competencies more ranked by position by adding the levels of importance that the competencies for the positions that a systems engineer can play according to the companies surveyed in Arequipa, Peru

\begin{tabular}{lccc}
\hline Competency & Developer & Analyst & System Administrator \\
\hline Teamwork & 47 & $\mathbf{5 1}$ & $\mathbf{5 1}$ \\
Leadership & 37 & 43 & $\mathbf{5 3}$ \\
Permanent learning & $\mathbf{5 3}$ & 46 & 46 \\
Verbal communication & 44 & $\mathbf{4 9}$ & 47 \\
Decision making & 40 & 45 & $\mathbf{4 9}$ \\
Delegation & 38 & 42 & 48 \\
Analytical ability & $\mathbf{4 9}$ & $\mathbf{4 8}$ & 45 \\
Pressure tolerance & 45 & 45 & 45 \\
Planification and organization & 47 & $\mathbf{5 0}$ & 48 \\
Innovation/Creativity & $\mathbf{4 8}$ & 47 & 46 \\
Emotional control & 41 & 46 & 44 \\
Autonomy/Initiative & 36 & 42 & $\mathbf{4 9}$ \\
Responsibility & $\mathbf{5 2}$ & $\mathbf{4 9}$ & $\mathbf{5 2}$ \\
Change/Adaptability & 43 & 45 & 42 \\
Use of technology & $\mathbf{5 0}$ & 44 & 45 \\
Systemic thinking & 46 & 43 & 44 \\
Mastery of skill and techniques & 43 & 45 & 44 \\
Resource management & 40 & 41 & 44 \\
Understand the system by viewing the full picture & 46 & 47 & 49 \\
Proactive role with administration & 35 & 42 & 46 \\
\hline
\end{tabular}

A dataset of more than 350 questions, with useful notes which serve as a guide for the user to answer a question, and more than 400 responses of the competencies selected for the practical module were organized to form the initial database of cases. The implemented system shows the competencies in a grid list with the alternative of selecting the number of questions desired by the user to practice (See Figure 2). In practice, the questions are shown in sequence, a guide can be selected by the user in order to get help about how to solve the practice questions or, in other cases, the user can skip the question to continue with the next one.

To give the user freedom and comfort and ensuring user practice, there is no restriction that the question should be answered before moving on to the next one. Feedback from the response entered by the user is processed by text mining and textual-CBR; The purpose of this process is to show the user a response similar to the one entered in order to analyze, observe and make a constructive criticism that serves as a reference to face a job interview. 

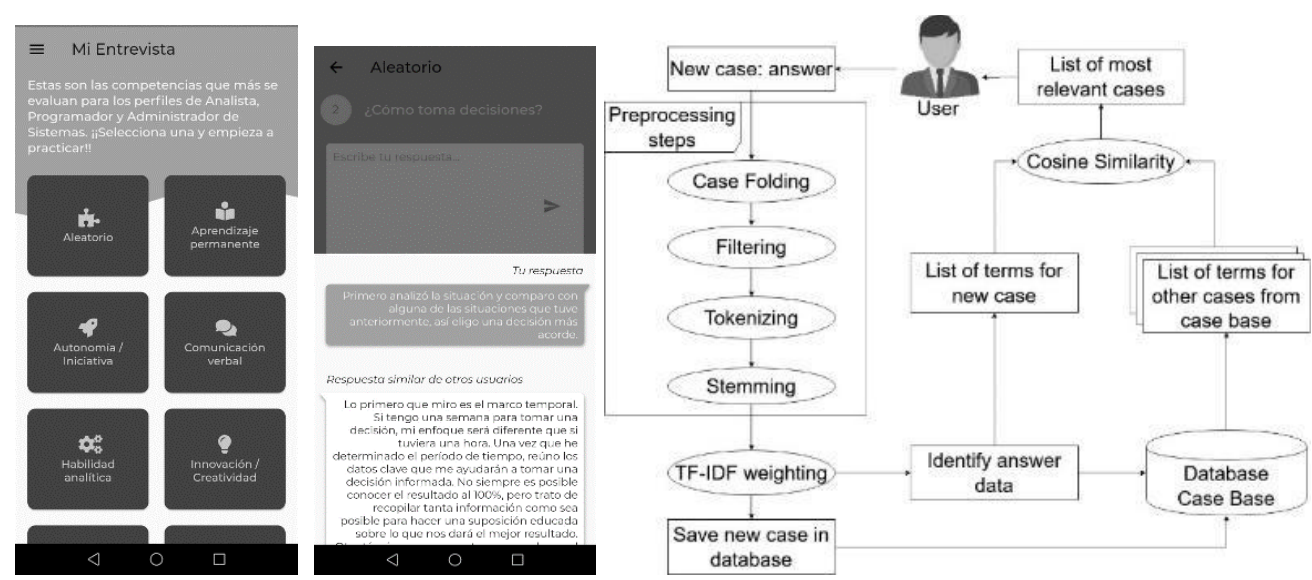

Figure 2. The practical module of the M-learning system. (left) Competencies selected are listed. (center) Feedback of the response entered by the user with a selected response using data mining and textual CBR is shown. (right) Workflow diagram of the process of recovering text data characteristics for textual cases

The application of artificial intelligence in the system is given in the practice module, where textual case-based reasoning is applied to the response entered by the user. The process workflow Textual-CBR (See Figure 2) is detailed below:

- New case: A response entered by the user to the case question presented in the M-learning system.

- Preprocessing steps:

- Case Folding: Converts text to lowercase and removes strange characters. Only letters from a to $\mathrm{z}$ including $\tilde{\mathrm{n}}$ are considered since the native language of the test subjects in Spanish.

- Filtering: Eliminates unnecessary words and replaces the remaining words compared with a B-tree of selected synonyms.

- Tokenizing: Generate a list of single and significant words to be processed.

- Stemming: Change the word into its base, eliminating prefixes, suffixes, and affixes (the Spanish Porter stemming algorithm is used).

- TF-IDF: TF-IDF is a method that works to weigh the term. TF (Frequency term) is the word weighting (term) that is based on the calculation of the number of words that appear in a document or case. IDF (Reverse Document Frequency) is the word weighting (term) that is based on the calculation of the number of words that appear in all documents or cases.

- Identify response data: Look for possible answers in the database for the case entered.

- Cosine Similarity: When the list of terms for the new case and other cases in the database are ready, a comparison is made with the cosine similarity to select a list of cases for the response. The cosine similarity is used to calculate the relevance approach to querying a document.

- List of most relevant cases: After comparing all cases with similarities, some cases are selected to show the user as feedback and suggestion, because in a job interview is difficult to talk about a correct response.

Tracking the preprocessing steps are useful for data mining of the response provided by the user and the responses found in the database. The answer is stored in the database for the recovery of a similar case with a later entry.

\section{RESULTS}

A questionnaire was used to evaluate the usability of the M-learning system and demonstrate whether it could be usable for the end-user, where tasks are evaluated with respect to the use of the theory and practice module, user satisfaction (Enriquez y Casas 2013) (López et al. 2017), as well as user confidence to face a job interview after using the system. 
Statistical demographic data. - The evaluation was made to 28 people; the population is made up of students and graduates. 54\% of the total are graduates, which indicates a greater predisposition to be evaluated in a job interview soon. According to gender data, the majority of the population surveyed belong to the male group (See Figure 4).
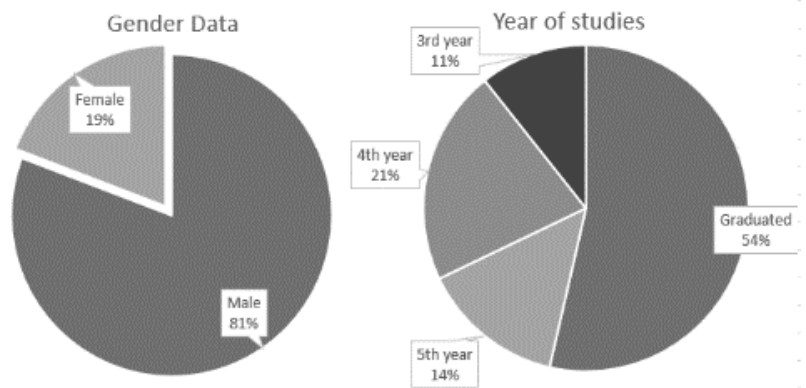

Figure 4. Statistical Demographic Data in the evaluation of the system m-learning

Task: Interact with the theory module. - The results obtained from the analysis of task 1 were positive, there is a high approval rate for this module (See Figure 5). It can be shown that most users have learned concepts about the job interview. We can affirm that the module fulfills its main objective. In the survey, a question was asked to verify the maximum range reached by each user to analyze the willingness to use the system, $21.4 \%$ of the population surveyed reached the beginner rank, indicating that they did not deepen or explore the module theory in greater detail, while more than $78 \%$ reached higher levels. The low inclination to the use of the theory module by a small part of the population could be due to several reasons, one of them could be that the system does not fit the individual's learning style. There are currently several investigations that indicate the importance to adjust the system to the learning style of an individual, this could be considered for future work.
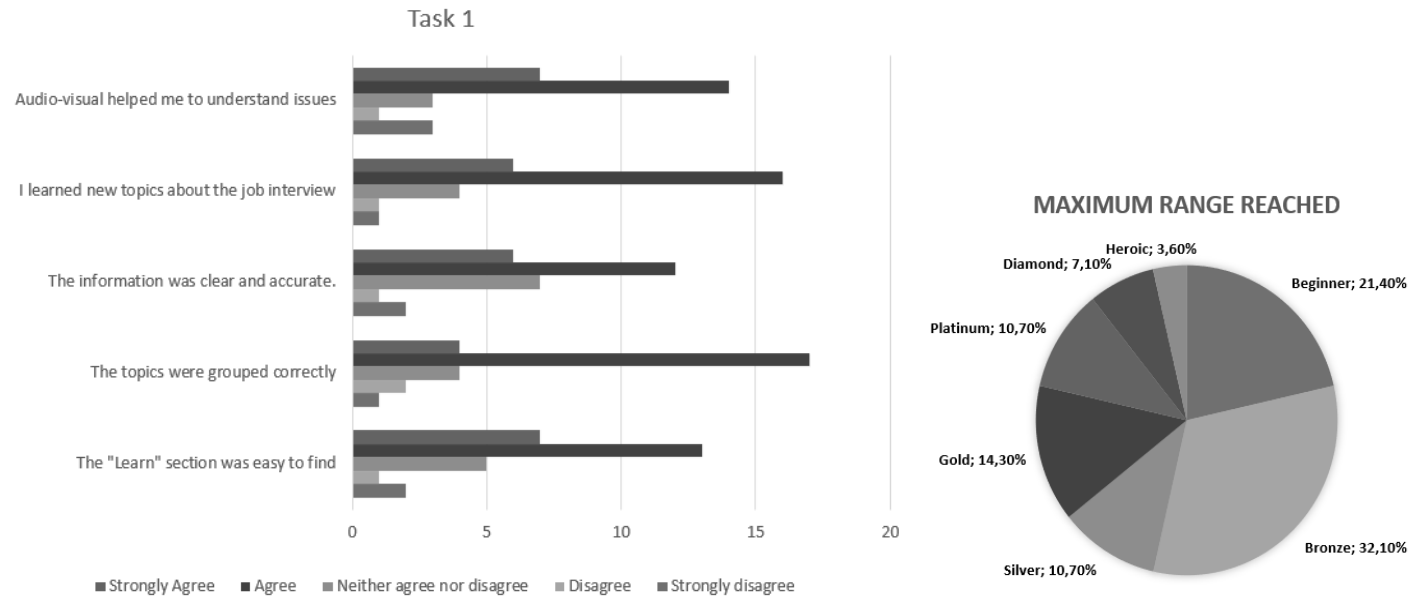

Figure 5. (first image) Evaluation of task 1: interact with the theory module (second image) Maximum range reached

Task 2: interact with the practical module. - The practical module had a high approval rate, that is, this module had more reception than the theory module. A large percentage of people evaluated indicated that the similar response offered by the system was very useful for analyzing and/or improving their response. We can affirm that the use of artificial intelligence techniques (CBR) in mobile learning can improve user learning and be a powerful tool.

The satisfaction of use. - The most prominent feature positively evaluated is the ease of use of the system, obtaining approval of $85.71 \%$. Nevertheless, there is a small part of the survey population that is undecided towards the use of the application (See Figure 6). 


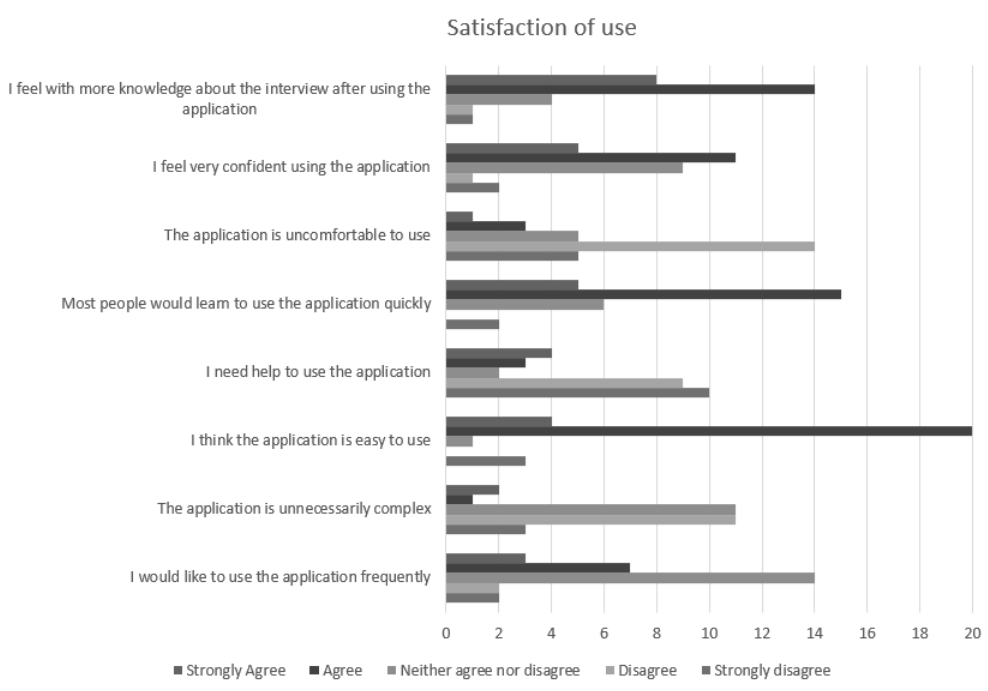

Figure 6. Evaluation of satisfaction of use

Positive effects. - One of the positive effects observed after the evaluation of the system was that a large part of the people evaluated felt that their level of confidence to face a job interview increased significantly after interacting with the system. This fact indicates that the M-learning system helps the applicant to gain more confidence to face a job interview. This will be a factor that plays an important role in a person's behavior when applying to a job. However, there are many other factors that could influence an interview, which could be taken into account for future work.

\section{CONCLUSION AND FUTURE WORK}

The increasing use of mobile devices and their characteristics at any time and any place make it an attractive tool for the user, developers, and researchers interested in M-learning. The application of textual reasoning based on cases helps to improve the processes of practice using cases that give a new approach to teaching.

It has been shown that the application of mobile technologies with artificial intelligence support allows the preparation of candidates for a better recruitment interview and selection of human talent, favoring learning, practice and providing them with more confidence.

Regarding future work, the following are proposed:

To future work, add the functionality of adapting the system to the user according to their learning styles through an evaluation test, in order to increase motivation and user interest in the system. Integrate emerging technologies as virtual, augmented or mixed reality for the practice process, simulating a real interview with a virtual realist interviewer. Integrate pedagogical agents that help guide the user to perform complex tasks and guide them through the platform.

\section{ACKNOWLEDGMENT}

We would like to thank UNSA-Investiga for the support provided for the development of this research work and the National University of San Agustin de Arequipa - UNSA for providing me with so many opportunities and enriching myself in knowledge. 


\section{REFERENCES}

Aamodt, A. and Plaza, E., 1994. Case-Based Reasoning: Foundational Issues, Methodological Variations, and System Approaches. AI Communications, vol. 7, no. 1, pp. 39-59.

Abutair, H.Y.A. and Belghith, A., 2017. Using Case-Based Reasoning for Phishing Detection. Procedia Computer Science, vol. 109, pp. 281-288.

Agreda, S.A., 2016. Nuevos retos en el reclutamiento y selección de personal: perspectivas organizacionales y divergencias éticas. Boletín Informativo CEI, vol. 1.

Ahmed, M.U. et al, 2008. Case-based Reasoning for Diagnosis of Stress Using Enhanced Cosine and Fuzzy Similarity. Transactions on Case-Based Reasoning for Multimedia Data, vol. 1, pp. 128-144.

Al-Ismail, M. et al, 2017. Effects of personality traits and preferences on M-learning. International Journal of Information Technology, vol. 9, no. 1, pp. 77-86.

Ally, M., 2007. Guest Editorial - Mobile Learning. The International Review of Research in Open and Distributed Learning, vol. 8, no. 2.

Alrasheedi, M. and Capretz, L.F., 2015. An Empirical Study of Critical Success Factors of Mobile Learning Platform from the Perspective of Instructors. Procedia - Social and Behavioral Sciences, vol. 176, pp. 211-219.

Álvarez, C.Á., 2012. La relación teoría-práctica en los procesos de enseñanza-aprendizaje. Educatio Siglo XXI, vol. 30, no. 2, pp. 383-402.

Blackman, M., 2009. The effective interview. Oxford University Press.

Blasco, R.D., 2004. Reclutamiento, selección de personal y las tecnologías de la información y de la comunicación. Revista de Psicología del Trabajo y de las Organizaciones.

Bourgeois, A. et al, 2016. How motivation and reward learning modulate selective attention. Progress in Brain Research, vol. 229, pp. 325-342.

Bridger, D., 2017. Neuro design: neuromarketing insights to boost engagement and profitability. London: Kogan Page.

Delany, S.J. and Bridge, D., 2006. Textual case-based reasoning for spam filtering: a comparison of feature-based and feature-free approaches. Artificial Intelligence Review, vol. 26, nos. 1-2, pp. 75-87.

Elhalwany, I. et al, 2014. Enhancements to knowledge discovery framework of SOPHIA textual case-based reasoning. Egyptian Informatics Journal, vol. 15, no. 3, pp. 211-220.

Enriquez, J.G. and Casas, S.I., 2013. Usabilidad en aplicaciones móviles. Informe Científico Técnico UNPA, vol. 5, no. 2, pp. $25-47$.

Facer, K. et al, 2004. Savannah: mobile gaming and learning?: Mobile gaming and learning. Journal of Computer Assisted Learning, vol. 20, no. 6, pp. 399-409.

Gerhana, Y.A. et al, 2017. The implementation of K-nearest neighbor algorithm in case-based reasoning model for forming automatic answer identity and searching answer similarity of algorithm case. 2017 th International Conference on Cyber and IT Service Management (CITSM), p. 1-5.

Gnana, A.A. et al, 2017. Mobile application for m-learning. International Journal of Advanced Research in Computer Science, vol. 8, no. 3, pp. 313-316.

Hamdani, D.S.A., 2013. Mobile Learning: A Good Practice. Procedia - Social and Behavioral Sciences, vol. 103, pp. 665-674.

Lopez, C.M.R. et al, 2017. Guía metodológica de pruebas especializada en control y calidad de aplicaciones móviles fundamentados en la norma ISO 9241-11 Ergonomic requirements for office work with visual display terminals (VDTS) 2016. Memorias de Congresos UTP, pp. 70-82.

Mcclelland, D.C., 1973. Testing for competence rather than for 'intelligence.' American Psychologist, vol. 28, no. 1, pp. 1-14.

Najwa Azmi, A. et al, 2018. Competencies of Engineering Graduates: What are the Employer's Expectations? International Journal of Engineering \& Technology, vol. 7, no. 2.29, p. 519.

Traxler, J., 2007. Defining, Discussing and Evaluating Mobile Learning: The moving finger writes and having writ .... The International Review of Research in Open and Distributed Learning, vol. 8, no. 2.

Weber, R.O. et al, 2005. Textual case-based reasoning. The Knowledge Engineering Review, vol. 20, no. 3, pp. 255-260.

Yorganci, S., 2017. Investigating Students' Self-Efficacy and Attitudes towards the Use of Mobile Learning. Journal of Education and Practice, vol. 8, pp. 181-185. 